\title{
ATORES E DISPUTAS: A QUEM INTERESSAM AS POLÍTICAS PÚBLICAS DO CAMPO EDUCACIONAL?
}

\author{
ACTORES Y CONTROVERSIAS: ¿A QUIÉN INTERESAN LAS POLÍTICAS PÚBLICAS \\ DEL ÁMBITO EDUCATIVO?
}

\section{ACTORS AND DISPUTES: WHO DOES THE PUBLIC POLICIES OF THE EDUCATIONAL FIELD INTEREST IN?}

DOI: https://doi.org/10.9771/gmed.v13i2.43326

\author{
Cristian Andrei Tisatto ${ }^{1}$ \\ Juliane Santana Bento ${ }^{2}$
}

\begin{abstract}
Resumo: O presente trabalho visa identificar quais os atores envolvidos e a influência de organizações sem fins lucrativos na formulação da Base Nacional Comum, no intuito de buscar compreender como se organizam, quais arenas ocupam e de que modo contribuíram ou não na formulação dessa política regulamentadora. Pretende, desse modo, identificar atores, como o Movimento pela Base Nacional Comum - que exerceu protagonismo na formulação de alternativas políticas - e associações, como a Associação Nacional de Pós-Graduação e Pesquisa em Educação (ANPEd) e a Associação Brasileira de Currículo (ABdC), que participaram da proposta de Base Nacional. $\mathrm{O}$ artigo também busca analisar os mecanismos e estratégias utilizadas para influenciar no processo de formulação, como o recurso e o financiamento disponível para os atores que disputaram projetos políticos, de implementação de novos paradigmas curriculares, utilizando como estratégia metodológica o estudo de caso, que possibilita uma análise concreta sobre como operam categorias como bottom up, accountaubility, atores políticos, assim como a participação de instituições não-estatais na formulação de políticas públicas.
\end{abstract}

Palavras-chave: Base Nacional Comum Curricular. Disputas. Formulação. Plano Nacional de Educação. Políticas públicas de educação.

Resumen: El presente trabajo tiene como objetivo identificar los actores involucrados y la influencia de las organizaciones sin fines de lucro en la formulación de la Base Común Nacional, con el fin de buscar entender cómo se organizan, qué espacios ocupan y cómo contribuyeron o no en la formulación de esta política regulatoria. De esta manera, se busca identificar actores, como el Movimiento por la Base Nacional Común - que jugó un rol protagónico en la formulación de alternativas políticas - y asociaciones, como la Asociación Nacional de Posgrados e Investigaciones en Educación (ANPEd) y la Asociación Brasileña de Currículos (ABdC), quien participó en la propuesta de Base Nacional. El artículo también busca analizar los mecanismos y estrategias que se utilizaron para incidir en el proceso de formulación, como el recurso y financiamiento disponible para los actores que disputaron proyectos políticos, implementando nuevos paradigmas curriculares, utilizando el estudio de caso como estrategia metodológica, lo que posibilita un análisis concreto de cómo operan categorías como bottom up, rendición de cuentas, actores políticos, así como la participación de instituciones no estatales en la formulación de políticas públicas.

Palabras clave: Base Curricular Nacional Común. Disputas. Formulación. Plan Nacional de Educación. Políticas públicas de educación.

Abstract: The present work aims to identify the actors involved and the influence of non-profit organizations in the formulation of the Common National Base, in order to seek to understand how they are organized, which arenas 
they occupy and how they contributed or not in the formulation of this regulatory policy. In this way, it intends to identify actors, such as the Movement for the Common National Base - which played a leading role in the formulation of political alternatives - and associations, such as the National Association of Graduate Studies and Research in Education (ANPEd) and the Brazilian Curriculum Association (ABdC), who participated in the National Base proposal. The article also seeks to analyze the mechanisms and strategies used to influence the formulation process, such as the resource and funding available to the actors who disputed political projects, implementing new curricular paradigms, using the case study as a methodological strategy, which enables a concrete analysis of how categories such as bottom up, accountaubility, political actors operate, as well as the participation of non-state institutions in the formulation of public policies.

Keywords: Common National Curricular Base. Disputes. Formulation. National Education Plan. Public education policies.

\section{Introdução}

O presente estudo busca identificar quais os atores envolvidos, bem como a influência de organizações sem fins lucrativos na formulação da Base Nacional Comum, buscando compreender como se organizam, quais arenas ocupam e de que modo contribuíram ou não na formulação dessa política regulamentadora. Esse processo envolveu uma série de atores, alguns visíveis e outros que não se apresentam de forma pública, mas atuam de forma determinante na formulação de políticas públicas. Afinal, quais os grupos de interesse e instituições financiadoras dessa proposta e quais mecanismos e estratégias foram adotados por determinados atores para influenciar no processo de formulação?

Por meio do presente estudo de caso (YAZAN, 2016), serão investigados os atores, interesses e disputas que cercam o chamado "Movimento Pela Base Nacional Comum", protagonista do processo de formulação da Base Nacional Comum Curricular, caracterizado por seus principais agentes representarem fundações ligadas ao meio empresarial, bem como associações ligadas ao campo educacional, sobretudo a ANPEd e a $\mathrm{ABdC}^{3}$, que se posicionaram contrariamente à formulação da referida política pública. Utilizou-se como referência para subsidiar a discussão documentos, notas e entrevistas concedidas a noticiários.

\section{O contexto de formulação das políticas públicas}

A formulação de alternativas para problemáticas que envolvem o coletivo atravessa uma série de discussões, disputas e tensões. O processo de decisão envolve a análise de um problema que, implicando ou afetando a vida de um grupo significativo de atores, acaba definindo agendas de decisões, ou seja, buscam-se alternativas e possibilidades de soluções, as quais, muitas vezes, encontram-se em stand by, já formuladas, à espera de a questão pautar as discussões e configurar a agenda, seja por interesse de gestores, por pressões e disputas de inúmeros atores e instituições que influenciam e dinamizam as relações do sistema de organização da gestão das políticas públicas. Uma destas recebe destaque, pela relevância, consequências e efeitos no desenvolvimento de um estado nacional: a educação brasileira, que apresenta indicadores que colocam em xeque a efetividade dos profissionais que nela atuam, além da estrutura das redes de educação do país, e do currículo escolar, que seguidamente é alvo de críticas e 
discussões sobre sua efetividade e sua participação na composição de indicadores nacionais e internacionais.

Um dos indicadores de maior relevância no cenário internacional coloca o Brasil na $60^{a}$ posição - de um total de 76 países - no ranking elaborado a partir de dados do Programa Internacional de Avaliação de Estudantes (PISA), que mede a qualidade da educação por meio de testes realizados pela Organização para a Cooperação e Desenvolvimento Econômico (OCDE). Tais indicadores, agregados a outros dados, remetem-nos a discussões primárias, como a função social da escola e a efetividade destas instituições em oferecer e promover educação de qualidade. A cada nova avaliação, discussões são travadas em torno de quais ideias serão selecionadas em uma "sopa de soluções": algumas "sobrevivem intactas, outras se confrontam e se combinam em novas propostas, outras ainda são descartadas" (CAPELLA, 2018, p. 97). Assim, emergem algumas ideias desta seleção, que farão parte da resolução, mediada e elaborada a partir do problema político a ser tensionado. Estas disputas, na formulação de alternativas, apresentam-se nas diferentes políticas públicas; a Educação vem fazendo tais seleções, a fim de aprimorar os processos e solucionar os problemas públicos sobre os quais vem sendo indagada.

Desde meados de 2014, uma reforma significativa na condução da política de educação brasileira vem sendo discutida: a reforma da educação a partir das diretrizes do currículo escolar, pauta que vem ocupando diversos espaços e diferentes arenas de políticas que, conforme Capella (2018, p. 53), "são posições institucionais onde decisões relativas a uma determinada questão são tomadas". Portanto, o currículo escolar brasileiro, que implicará na alteração dos Projetos Políticos Pedagógicos e seus respectivos currículos de 181 mil instituições, vem sendo motivo de disputas, negociações e barganhas, buscando a efetivação de uma política pública regulatória, prevista na Constituição Federal de 1988 (BRASIL, 1988) e ratificada na Lei de Diretrizes e Bases da Educação Nacional (BRASIL, 1996), datada de 1996. No entanto, foi a partir da elaboração e discussão do Plano Nacional de Educação, que é um Plano Decenal, elaborado com uma série de metas e diretrizes que norteiam o funcionamento e a estrutura da Educação brasileira, que o currículo volta à discussão, assim como uma BNCC - ou seja, um currículo unificado para todo o país volta a ser pauta de comunidades políticas, ou policy communities (CAPELLA, 2018, p. 6), as quais consistem em comunidades de especialistas que defendem perspectivas de grupos de interesses, que passam a uma disputa de ideologias, valores e forças políticas.

A Base Nacional, um documento de caráter regulatório que envolve a tomada de decisões, além da burocracia do Estado e os grupos de interesses, tem como função regular a formação dos currículos locais, estabelecendo objetivos, competências e habilidades mínimas que deverão ser seguidas pelos diferentes sistemas de ensino que compõem a rede de educação básica brasileira. O documento propõe, conforme ele próprio se define:

a Base Nacional Comum Curricular é um documento de caráter normativo que define o conjunto orgânico e progressivo de aprendizagens essenciais que todos os alunos devem desenvolver ao longo das etapas e modalidades da Educação Básica. Conforme definido na Lei de Diretrizes e Bases da Educação Nacional (LDB, Lei no 9.394/1996), 
a Base deve nortear os currículos dos sistemas e redes de ensino das Unidades Federativas, como também as propostas pedagógicas de todas as escolas públicas e privadas de Educação Infantil, Ensino Fundamental e Ensino Médio, em todo o Brasil. (BRASIL, 2017).

Desse modo, no período entre 2014 e 2018, este último sendo o ano da homologação da segunda parte da Base Nacional ${ }^{4}$, ocorreram diferentes processos, disputas e tensões nas discussões que pautaram a formulação desta, que foi tratada pelo Plano Nacional de Educação (PNE) como uma das estratégias para a melhoria da qualidade da educação nacional nele garantida.

2.1) O Ministério da Educação, em articulação e colaboração com os Estados, o Distrito Federal e os Municípios, deverá, até o final do $2^{\circ}$ ano de vigência deste PNE, elaborar e encaminhar ao Conselho Nacional de Educação, precedida de consulta pública nacional, proposta de direitos e objetivos de aprendizagem e desenvolvimento para os(as) alunos(as) do ensino fundamental; 2.2) Pactuar entre União, Estados, Distrito Federal e Municípios, no âmbito da instância permanente de que trata o $\int 5^{\circ}$ do art. $^{\circ} 7^{\circ}$ desta Lei, a implantação dos direitos e objetivos de aprendizagem e desenvolvimento que configurarão a base nacional comum curricular do ensino fundamental. (BRASIL, 2014, grifo do autor).

Durante o processo de construção do documento regulatório, denominado Base Nacional Comum Curricular, diversos atores se mobilizaram e buscaram formas de articulação, na tentativa de defender interesses, ideologias e buscar a institucionalização de suas ideias no campo da educação. $\mathrm{Na}$ seção a seguir, serão tratados os atores que compunham esses polos em disputa no processo de elaboração da BNCC.

\section{A politica educacional em disputa: atores, grupos de interesse e comunidade política}

O conflito, o interjogo ocorrido neste processo apresentou-se a partir do questionamento de associações acadêmicas, como a ANPEd e a ABdC, os sindicatos, a Confederação Nacional dos Trabalhadores em Educação (CNTE), acerca da ideia mercadológica que estaria por trás de todo o movimento de mobilização da Base Nacional, como a busca por resultados. De certo modo, esses movimentos são pautas de determinados governos e provocam as reformas da educação desde meados de 1995, quando o Brasil adotava avaliações de larga escala como requisito para a obtenção de financiamentos de instituições internacionais.

Em contrapartida, outros sujeitos, vinculados a organizações e entidades sem fins lucrativos, mobilizaram gestores, financiaram conferências e organizaram formas de publicização midiática da proposta de formulação da BNCC. Tais grupos de interesse chamam a atenção pelo protagonismo que exerceram, tanto que criaram um movimento denominado "Movimento pela Base Nacional Comum", que articulou a formulação da proposta e organizou estratégias de mobilização nos diferentes espaços políticos. O "Movimento pela Base Nacional Comum" teve dentre seus membros instituições importantes no cenário mercadológico, que o financiaram e se tornaram participantes no processo de empreender e 
interferir neste instrumento regulatório da política pública. Empresas e fundações, como aponta Corrêa e Morgado (2018, p. 6):

\begin{abstract}
Com maior ou menor protagonismo, entre os diversos parceiros estão as seguintes entidades: Itaú, Unibanco, Bradesco, Santander, Gerdau, Natura, Fundação Victor Civita, Fundação Roberto Marinho, Camargo Corrêa, Fundação Lehmann e Todos pela Educação e Amigos da Escola. De entre os agentes privados despontou, com protagonismo, a Fundação Lemann, de Jorge Paulo Lemann, um dos controladores da cervejaria Anheuser-Busch InBev e do fundo de participações 3G Capital (dono do Burger King, Americanas, Submarino, Shoptime e da Heinz) (CORREAA; MORGADO, 2018, p. 6).
\end{abstract}

Daí a necessidade de investigação de como esses agentes contribuíram na formulação dessa alternativa - já prevista em lei, mas que desde 2014 é incluída na agenda governamental e tem suas discussões e formulação impulsionadas por diferentes atores e grupos de interesse. A Ciência Política ocupa-se das disputas, conflitos e tensões que rondam os processos de construção de políticas. Mas cabe, aqui, ressaltar que se limitou, por longo período, a compreender o funcionamento e a dinâmica do Estado, especificamente, de forma desvinculada a outros segmentos e grupos de interesse, como o mercado financeiro. Recentemente, análises mais amplas, elaboradas a partir de estudos sobre as políticas públicas, passaram a fazer parte de estudos e referências produzidas, tensionando e atentando-se a quais sujeitos que participam da construção desta alternativa à política pública, em como ocorreram as interferências, além do papel que estes exercem na condução destas, identificando se atua de forma pública ou invisível (CAPELLA, 2018)

É na década de 1990 que a literatura passou a trabalhar com um conceito da Ciência Política New Public Management -, que consiste em incorporar ações e princípios liberais, advindos do capitalismo e adotados nas grandes corporações, ou seja, adotam-se novas práticas de gestão pública, seguindo uma lógica empresarial que se baseia em princípios do mercado, focando nos resultados (BENTO, 2018). Os governos passam a buscar o exercício de uma governança que atenda às exigências de entidades de financiamento público, como fundos internacionais, a exemplo do FMI e do Banco Mundial.

Nessa nova configuração da gestão das políticas públicas, um novo protagonista se apresenta, aliando-se à gestão de governo e das políticas: o mercado, que, no presente estudo, se destaca através de instituições privadas, sem fins lucrativos. O mercado, que tem como princípio o lucro, a busca por competitividade e os resultados, buscando implementar princípios de transparência e equidade, bem como facilitar/otimizar o acesso e a distribuição de recursos. Diante disso a isso, a Fundação Lemann, por exemplo, acredita que "Advindos da área empresarial e sabendo da importância da avaliação de resultados, acreditamos que um foco similar, mas adaptado à educação, trará grandes benefícios” (FUNDAÇÃO LEMANN, 2002, p. 04). É evidente que as lógicas de governança do mundo dos negócios, do mundo empresarial acaba, portanto, influenciando nas decisões e na formulação de políticas.

A educação brasileira, diante dessa nova perspectiva, enquanto política pública, mostrava-se à margem, na tangente, destes processos até a década de 1990. No entanto, com a aprovação de legislações, 
como a Lei de Diretrizes e Bases (BRASIL, 1996), e a organização dos Parâmetros Curriculares Nacionais, elaborados em 1998 para nortear a organização de currículos locais, vislumbrava-se a possível intervenção dos princípios do mercado na educação, que se inicia com o movimento de construção de um parâmetro de currículo, que contemplasse objetivos comuns aos diferentes territórios e localidades do país.

Alguns estudiosos, a exemplo de Marinho (2003), ressaltam que a construção dos Parâmetros Curriculares Nacionais, os PCN’s, marcam o início da lógica do capital e do neoliberalismo na educação pública. A partir daí, sugerem que se inicia a aplicação de avaliações de larga escala, algumas destas aplicadas por Organizações Internacionais que se utilizavam dos dados para aprovação ou não de financiamento para grandes projetos de governantes do país. Adota-se, portanto, uma política de accountability, que tem como fundamento a transparência e responsabilização dos agentes públicos, bem como a prestação de contas das ações, não se restringindo somente aos burocratas. Pelo contrário, expande a lógica da transparência a todos os agentes envolvidos no processo de governança. É relevante destacar que a educação, desde a implementação de avaliações externas, medidas por organismos internacionais, vem sendo cobrada pelos resultados. Cada vez mais, ocupa status de problema público e político, sendo, portanto, incorporada às agendas e à formulação de alternativas.

A gestão da política pública educacional passou a ser analisada a partir de uma lógica de resultados, adotados e exigidos pelo Fundo Monetário Internacional (FMI) e pelo Banco Mundial como requisito para investimentos no país. Isto, de certo modo, justifica a interferência da iniciativa privada e de organizações sem fins lucrativos no sistema público de ensino. Explica, também, a competitividade estabelecida no contexto educacional. Em busca de melhores índices e resultados, a área reinventa-se e questiona suas diretrizes, que perpassam questões práticas como a carga horária diária de aulas, até os currículos e as ideologias, contempladas ou não nestes documentos. Até o ano de 2014, tais diretrizes eram elaboradas a partir de parâmetros curriculares datados de 1997. Após 2014, com a promulgação do Plano Nacional de Educação - e o estabelecimento de metas e estratégias, visando à qualidade da educação -, a BNCC é percebida como necessária e passa a ser construída com a mobilização de comunidades políticas. A tônica preponderante passa a ser a busca por apresentar melhores resultados, ou seja, adotando uma estratégia de formação pública orientada por metas de alegada qualidade de ensino política de prestação de contas.

Todavia, essa elaboração gera uma série de controvérsias, tensões e disputas. Alguns agentes desse processo, através de financiamento empresarial, travam campanhas pelo país, financiando gestores da educação, assessores, especialistas e representantes de diferentes grupos de interesses, entre outros atores, oriundos de comunidades de políticas, as quais

são compostas por especialistas que se ocupam de uma determinada área, como pesquisadores, consultores, assessores parlamentares, funcionários governamentais, analistas vinculados a organismos internacionais, ONGs, grupos de interesse, etc. Nelas, as propostas de políticas públicas podem surgir, ser abandonadas ou combinadas entre sí, ou podem permanecer intactas e sobreviver (RUA; ROMANINI, 2014, p.16). 
Essas comunidades políticas organizadas e os sujeitos envolvidos na formatação de um documento desta relevância remete-nos à história da educação, que se pautou em disputas e jogos de interesse envolvendo diferentes grupos, valores e interesses bastante diversos. No entanto, Michetti (2018; 2020), estudiosa das relações entre atuação pública de organizações e elites empresariais, destaca que:

Atualmente, um dos agentes que tomam parte nessas disputas são organizações sem fins lucrativos ligadas ao universo corporativo. Elas atuam de diversas formas, como em parcerias com secretarias municipais e estaduais de educação, na formação de "líderes", em premiações de "boas práticas", no financiamento de pesquisas na área de educação e na formação de "coalizões" para a consecução de políticas educacionais de amplo escopo, como a criação da chamada "Base Nacional Comum Curricular" (MICHETTI, 2018, p. 2).

Uma série de posicionamentos contrários à formulação de uma Base Nacional organizam-se a partir de atores que participam, de formas diversas, do processo de formulação. Associações como a ANPEd corroboram a crítica na medida em que expõe alguns argumentos para o debate, publicados em nota oficial e encaminhados ao Conselho Nacional de Educação. No manifesto, a associação de pesquisadores em Educação questiona desde a legitimidade do processo de construção do documento, que, a priori, contara com a ampla participação de especialistas e de um grupo pequeno para a sua composição e elaboração, até a ruptura ocorrida em 2016, com o impeachment da Presidenta Dilma Rousseff.

Outro fator destacado no documento emitido pela ANPEd diz respeito ao fato de a BNCC ter sido homologada em diferentes tempos, de forma fragmentada. A Educação Infantil e o Ensino Fundamental tiveram a homologação da Base em 2017, no mês de dezembro. Já a etapa do Ensino Médio, considerada etapa obrigatória, só foi contemplada em 2018, após muitas discussões, e teve uma única versão apresentada publicamente para discussão, tendo sido, na sequência, homologada com celeridade. Outras questões mencionadas na nota versam sobre a democratização da escola, sua função social no desempenho de papeis fundamentais no combate à desigualdade e na construção da singularidade dos sujeitos. No conjunto de valores que enunciam, a nota permite a constatação de que, para a ANPEd, a BNCC trata-se de uma política pública elaborada a partir de uma abordagem top down, sem que tenha havido a troca de informações necessárias e a construção colaborativa dos profissionais que efetivamente atuam no espaço escolar.

O modelo top down segue uma ideia weberiana, que se relaciona à organização e burocracia. Nessa perspectiva, a política adotada é centralizada na figura dos tomadores de decisão, os burocratas de alto-escalão, que desconsideram a participação dos burocratas de guichê. Ou seja, as decisões são tomadas e a política implementada de modo que as decisões daqueles que estão acima nas hierarquias sejam mantidas, sem que haja um ideal de reciprocidade, de intercâmbios entre os agentes que implementarão a política. O fato de a política da BNCC ser enquadrada na categoria de análise de política top down é evidenciado, junto à preocupação da ANPEd e $\mathrm{ABdC}$ no seguinte trecho de um estudo realizado e 
publicado pelas associações, de modo a sinalizar o posicionamento para a Secretaria de Educação Básica (SEB) do Ministério da Educação (MEC):

Nossa posição é sustentada no entendimento de que a desejável diversidade, fundamental ao projeto de nação democrática expresso na Constituição Brasileira e que se reflete na LDB/1996, não é reconhecida na proposta da BNCC, na medida em que nesta está subentendida a hegemonia de uma única forma de ver os estudantes, seus conhecimentos e aprendizagens, bem como as escolas, o trabalho dos professores, os currículos e as avaliações, imprópria à escola pública universal, gratuita, laica e de qualidade para todos. Entendemos que o documento Base Nacional Comum Curricular apresenta, naquilo que Ítalo Dutra, Diretor de Currículos e Educação Integral da SEB/MEC, denomina 'estrutura do documento e de seus fundamentos', uma descaracterização do estudante em sua condição de diferença, bem como da desumanização do trabalho docente em sua condição criativa e desconsideração da complexidade da vida na escola. A conversão do direito a aprender dos estudantes numa lista de objetivos conteudinais a serem aprendidos retira deste direito seu caráter social, democrático e humano. Apesar das constantes críticas dos especialistas da área, constatamos que, ao longo destes últimos dois anos, progressivamente, o MEC foi silenciando sobre os debates, avanços e políticas no sentido de democratização e valorização da diversidade, cedendo voz ao projeto unificador e mercadológico na direção que apontam as tendências internacionais de uniformização/centralização curricular + testagem larga escala + responsabilização de professores e gestores traduzido na BNCC e suas complementares e hierarquizantes avaliações padronizadas externas. Como já viemos verificando em estudos e debates nacionais e internacionais, essa tríade orientada para os valores do mercado tem gerado, consequentemente, a desvalorização e privatização dos sistemas públicos de ensino e seus atores em diversas dimensões. (ANPED, 2015, p. 2).

A nota ainda alerta sobre o silenciamento de instituições de participação, além de expor preocupação com o caráter mercadológico, defendido por atores que, na arena de disputa, se posicionaram a partir de outros grupos de interesses, travando um jogo com as organizações sem fins lucrativos, mas com interesses na área educacional. Fontes jornalísticas se propuseram a uma investigação sobre os interesses e agentes envolvidos na formulação deste documento. A Escola Politécnica de Saúde Joaquim Venâncio (EPSJV), que é uma unidade técnico-científica da Fiocruz, destacou, em uma reportagem intitulada "A quem interessa a BNCC", publicada em 23 de novembro de 2017, a fala do presidente do Banco Central, Ilan Goldfajn, em entrevista concedida ao veículo de comunicação CBN. Goldfajn "listou como um dos motivos para o aumento da confiança de investidores e investidores estrangeiros na economia brasileira - auferida por Goldfajn durante reuniões realizadas em Nova York - a "reforma da educação" (ANTUNES, 2017). Evidencia-se, então, um interesse das organizações sem fins lucrativos, a exemplo da Fundação Lemann, integrante do Movimento pela Base Nacional Comum, que financiou parlamentares no ano de 2013, garantindo a participação destes em um seminário, realizado pela Universidade de Yale, em parceria com a Fundação Lemann, que tratava sobre o Common Core. Por Common Core compreende-se uma unificação do currículo adotado em escolas norte-americanas, ou seja, o estabelecimento de um núcleo comum, mas restrito a contemplar apenas áreas de conhecimento que constam nas avaliações internacionais, como o PISA. É importante salientar que um dos atores financiados pela Fundação Lemann, que participou do Seminário nos Estados Unidos, é também 
integrante do Movimento pela Base Nacional Comum: o deputado federal Alex Canziani (PTB), que preside a Frente Parlamentar da Educação.

Quem são os atores sociais e os grupos de interesse que interferiram na definição da BNCC? A Base Nacional envolveu diferentes atores e comunidades de política nas discussões, no entanto, há aqueles que se mostraram protagonistas dos processos, como o Movimento pela Base Nacional Comum. Outros, mobilizados no pólo contrário, com menor protagonismo e participação, podem ser identificados como os grupos em torno da ANPEd, da $\mathrm{ABdC}$, dentre outras associações e sindicatos que colaboraram com algum mecanismo de participação, porém sem ocupar posições de protagonismo.

Conforme o próprio site do Movimento pela Base Nacional Comum - um grupo de interesse envolvido nas discussões sobre a BNCC, que participa ativamente como apoiador do Movimento é o Instituto Unibanco (Itaú). Em artigo no Valor Econômico de 26 de janeiro de 2015, intitulado "Educação, Produtividade e Crescimento", escrito por um economista do Instituto Unibanco, afirma-se que:

Com condições iniciais melhores, somadas a outras políticas, os resultados vêm aparecendo. A taxa de mortalidade infantil até 5 anos caiu de 61 (em mil) em 1990, para 16 em 2014. Partindo de condições melhores na primeira infância, as crianças/adolescentes acabam ficando mais tempo na escola. Em 1992 os brasileiros estudavam 4,8 anos, em média. Em 2014, o número subiu para 8 anos. Com esses resultados, a produtividade da mão de obra no Brasil deveria estar aumentando, contribuindo para o crescimento do PIB potencial do país. No entanto, as estimativas de evolução da produtividade calculadas a partir das contas nacionais e dos números do mercado de trabalho sugerem que, na melhor das hipóteses, a produtividade ficou constante (MEGALE, 2016).

Destaca-se, então, a "produtividade da mão de obra" e o fato de a educação estar associada a este princípio. Essa perspectiva vai de encontro à preocupação da ANPEd, da $\mathrm{ABdC}$, dentre outras que se pronunciaram oficialmente, alegando a mercantilização da educação e afirmando interesses de grupos econômicos na privatização e na adoção da lógica empresarial no sistema público de ensino, o que descaracterizaria as singularidades de cada escola pública, havendo um processo de homogeneização do currículo, que legitimaria, na medida em que dissimula, as desigualdades em seus mais diversos desdobramentos.

O Movimento pela Base Nacional Comum é um dos protagonistas do processo de construção da Base Nacional Comum - que investe maciçamente na publicização da proposta - e atua, oferecendo aos municípios, aos Estados e ao Distrito Federal, formações que compõem jornadas pedagógicas, seminários, simpósios e congressos de formação de professores, além de oferecer apoio, materiais e formações para a União Nacional dos Dirigentes Municipais de Educação (UNDIME), o Conselho Nacional de Secretários de Educação (CONSEd) e assessores do Ministério da Educação, visando à divulgação da proposta e sua formulação, bem como à posterior implementação, de acordo com os princípios e valores adotados pelo Movimento, que se define como

um grupo não governamental de profissionais da educação que desde 2013 atua para facilitar a construção de uma Base de qualidade. O grupo promove debates, produz 
estudos e pesquisas com gestores, professores e alunos e investiga casos de sucesso em vários países. ${ }^{5}$

Chama à atenção os financiadores e apoiadores deste projeto, tendo em vista que, conforme o site do Movimento, este tem o apoio de várias organizações, destacadas a seguir, no Quadro 1:

Quadro 1 - Organizações que apoiam o Movimento pela Base Nacional Comum

\begin{tabular}{|c|c|}
\hline Instituição & Descrição \\
\hline Abave & $\begin{array}{l}\text { Espaço plural e democrático para o intercâmbio de experiências entre } \\
\text { os acadêmicos e os implementadores da avaliação educacional. }\end{array}$ \\
\hline Cenpec & $\begin{array}{l}\text { Organização da sociedade civil, sem fins lucrativos, que tem como } \\
\text { objetivo o desenvolvimento de ações voltadas à melhoria da qualidade } \\
\text { da educação pública e à participação no aprimoramento da política } \\
\text { social. }\end{array}$ \\
\hline Comunidade Educativa Cedac & $\begin{array}{l}\text { Apoia profissionais da educação no desenvolvimento de } \\
\text { conhecimentos e práticas que resultem na oferta de uma educação } \\
\text { pública de qualidade. }\end{array}$ \\
\hline Fundação Lemann & $\begin{array}{l}\text { Organização familiar sem fins lucrativos que desenvolve e apoia } \\
\text { projetos inovadores em educação; realiza pesquisas para embasar } \\
\text { políticas públicas no setor e oferece formação para profissionais da } \\
\text { educação e para o aprimoramento de lideranças em diversas áreas. }\end{array}$ \\
\hline Consed & $\begin{array}{l}\text { O Conselho Nacional de Secretários de Educação congrega, por meio } \\
\text { de seus titulares, as Secretarias de Educação dos Estados e do Distrito } \\
\text { Federal. }\end{array}$ \\
\hline $\begin{array}{l}\text { Fundação Maria Cecília Souto } \\
\text { Vidigal }\end{array}$ & $\begin{array}{l}\text { Organização familiar sem fins lucrativos que atua pelo pleno } \\
\text { desenvolvimento da criança na primeira infância (fase do nascimento } \\
\text { até } 6 \text { anos). Dedica-se a atividades de conscientização da sociedade, } \\
\text { mobilização de lideranças, apoio à qualificação da educação infantil e } \\
\text { programas de atenção às famílias. }\end{array}$ \\
\hline Fundação Roberto Marinho & $\begin{array}{l}\text { Entidade sem fins lucrativos voltada para a educação e o } \\
\text { conhecimento que contribui com o desenvolvimento da cidadania. }\end{array}$ \\
\hline Instituto Ayrton Senna & $\begin{array}{l}\text { Organização sem fins lucrativos que trabalha para ampliar as } \\
\text { oportunidades de crianças e jovens por meio da educação. }\end{array}$ \\
\hline Instituto Inspirare & $\begin{array}{l}\text { Instituto familiar que tem como missão inspirar inovações em } \\
\text { iniciativas empreendedoras, políticas públicas, programas e } \\
\text { investimentos que melhorem a qualidade da educação no Brasil. }\end{array}$ \\
\hline Instituto Natura & $\begin{array}{l}\text { Executa e apoia projetos voltados à melhoria da Educação Básica da } \\
\text { rede pública, no Brasil e na América Latina, que sejam pautados na } \\
\text { eficácia da aprendizagem, na equidade de resultados e na coesão } \\
\text { social. }\end{array}$ \\
\hline Itaú BBA & $\begin{array}{l}\text { O Itaú BBA é o maior banco de investimento corporativo da América } \\
\text { Latina e faz parte do grupo Itaú Unibanco. }\end{array}$ \\
\hline Instituto Unibanco & $\begin{array}{l}\text { Visa ampliar as oportunidades educacionais dos jovens em busca de } \\
\text { uma sociedade mais justa e transformadora, focando sua atuação na } \\
\text { melhoria do Ensino Médio. }\end{array}$ \\
\hline Todos Pela Educação & Movimento da sociedade brasileira que tem como missão contribuir \\
\hline
\end{tabular}




\begin{tabular}{|l|l|}
\hline Undime & $\begin{array}{l}\text { para que até 2022, ano do bicentenário da Independência do Brasil, o } \\
\text { País assegure a todas as crianças e jovens o direito a Educação Básica } \\
\text { de qualidade. }\end{array}$ \\
\hline $\begin{array}{l}\text { A União Nacional dos Dirigentes Municipais de Educação é uma } \\
\text { associação civil, fundada em 1986, que reúne dirigentes municipais de } \\
\text { educação para construir e defender a educação pública com qualidade } \\
\text { social. }\end{array}$ \\
\hline
\end{tabular}

Fonte: elaboração própria 6 .

É importante destacar que, destes autores, a UNDIME, o CONSEd e o MEC estiveram representados os três níveis federativos (municipal, estadual e federal). No legislativo, a Comissão de Educação teve centralidade no processo, por discutir os rumos da educação, trazendo à tona questões de gênero e do movimento Escola Sem Partido.

Um dos apoiadores do Movimento pela Base, Paulo Lemann, é indicado pela revista Forbes como um dos maiores bilionários do Brasil. A discussão travada pelas entidades do Quadro 1 que defenderam a instauração da Base Nacional seria a melhoria da qualidade da educação pública através da uniformização e adoção de princípios corporativos na gestão da política educacional. Exemplo disso é a aposta que fazem na premiação de professores, estimulando a competição pelo reconhecimento de projetos que bonificam propostas desenvolvidas por docentes da rede pública. Um concurso ilustrativo desse modelo de distinção do trabalho docente é o chamado "Educador Nota 10".

Os atores sociais contrários a esse paradigma defendem uma educação pública isenta de interferências do mercado, do capital e desvinculados do new public management, sem necessariamente vincular educação, enquanto política pública, aos princípios de mercado. A ideia do Movimento pela Base Nacional Comum é reforçada em alguns documentos, como na nota cita a seguir, na qual aponta-se a preocupação com as avaliações externas, além da observação em relação à produção de materiais didáticos. Cumpre mencionar que é constante a preocupação das associações da Educação com a ênfase dos atores comprometidos com a formulação da BNCC sobre a disponibilização de repositórios didáticos, visto que há, do ponto de vista do mercado editorial, uma pressão e altos investimentos na produção e comercialização de materiais didáticos.

A ausência desta base enseja também que as avaliações externas como a Prova Brasil assumam de fato um papel de prescrição da base curricular nacional, quando o contrário deveria ocorrer - a Prova Brasil deveria ser a forma de a sociedade verificar se os estudantes tiveram, de fato, seus direitos de aprendizagem garantidos. A ausência de uma linguagem curricular comum, em particular de orientações legais explícitas a respeito do que os alunos precisam aprender em cada fase da escola, também dificulta a produção e organização de materiais didáticos e a formação inicial e continuada de professores. (MOVIMENTO PELA BASE NACIONAL COMUM, 2019).

A preocupação com o mercado editorial e o apoio de entidades sem fins lucrativos, mas ligadas a grandes corporações, coloca em questão a presença destas instituições na política educacional brasileira, visto que, conforme dados do Senado Federal, estudos realizados acerca do Programa Nacional do Livro 
Didático (PNLD) mostraram que este programa representa cerca de 54\% da indústria nacional de livros, que se restringe a seis grupos de editoras, algumas atuando internacionalmente (BRITTO, 2011).

Michetti (2018) evidencia que o Movimento pela Base Nacional Comum é financiado por um conjunto de organizações que exerceram posição central nas discussões, tendo em vista que

tais organizações são bastante representativas de agentes que ocuparam posições centrais no espaço social dos debates sobre a BNCC. Nesse espaço social, os agentes em posição dominante, como o poder público, as fundações privadas e as empresas, contam com maior montante de capital político, social e econômico. (MICHETTI, 2018, p. 7).

Esse investimento de organizações sem fins lucrativos, mas com grande capital econômico e social, legitimam essas instituições e o Movimento em uma condição de maior participação. Diante da possibilidade de financiamento para a formulação e implementação, MEC, CONSEd e UNDIME cedem às benesses e estruturas econômicas destas instituições. Nesse sentido, o protagonismo evidencia-se pela capacidade de financiamento, em especial do Movimento pela Base Nacional Comum: dispondo de maior capital econômico, tem assegurada a facilidade de trânsito, reforçada pelos integrantes que ocupam cargos parlamentares e circulam nos espaços de poder como o Congresso Nacional.

O Movimento pela Base Nacional Comum coloca-se diante dos questionamentos, buscando legitimidade a partir de duas abordagens: afirmando ser um representante da sociedade civil e pela sua composição técnica, formado, portanto, por especialistas. O Movimento reforça a ideia defendida por alguns estudiosos, de que as políticas públicas, as alternativas e as formulações de alternativas não se restringem somente ao Estado, mas mobilizam atores externos à máquina burocrática deste, com a participação de agentes, alguns públicos, como o Movimento pela Base Nacional Comum, mas que é financiado por atores invisíveis, que estão por trás destas instituições.

Atores exercem poder de influência na definição de alternativas políticas. Nesse contexto, o Movimento pela Base (MpB) é um ator visível que exerce papel no fluxo da política pública (CAPELLA, 2018). Nessa condição, recebe atenção da mídia, mantém relação com a arena política, exposto às pressões da opinião pública, que inclui atores das diferentes esferas do poder, como o executivo, o legislativo e outras forças que buscam discutir e questionar a legitimidade de atuação ou a definição de soluções.

Já os atores invisíveis seriam aqueles do qual fazem parte os burocratas, grupos de interesse, pesquisadores, partidos políticos, mídia e opinião pública, que não necessariamente se apresentam no jogo. Esse segundo fluxo abrangeria a dimensão política, que envolve as barganhas e as negociações. Assim, as entidades financiadoras do Movimento pela Base Nacional Comum exercem também um papel invisível e de importante função articuladora e financiadora, garantindo, através do financiamento de projetos, a negociação necessária à formulação de alternativas.

Em contraponto ao protagonismo exercido pelo Movimento pela Base Nacional Comum, encontram-se dados que 
segundo o portal do MEC, foram recebidas mais de 12 milhões de contribuições individuais, de organizações e de redes de educação de todo o País -, além de pareceres analíticos de especialistas, associações científicas e membros da comunidade acadêmica. Os professores puderam participar em duas categorias, como sujeitos na categoria "Indivíduos" e também enquanto profissionais integrantes de uma escola/rede de ensino na categoria "Redes". Nesta última categoria é possível constatar o baixo índice de participação, tendo em vista o portal registrar apenas 45.049 escolas, sendo que, conforme censo de 2016, o País conta com 186,1 mil escolas de Educação Básica (TRICHES, 2018, p. 73).

Nessa perspectiva, a participação das escolas públicas foi quantitativamente pouco relevante. Já as instituições constituídas por grandes empresas têm se articulado com uma proposta de educação global, sob influência de grandes potências como os Estados Unidos.

\begin{abstract}
Nessa mesma direção, o Brasil vem seguindo os moldes internacionais de pensar o currículo. Sujeitos individuais e coletivos, organizados em instituições públicas e privadas, vêm se articulando por meio de seminários, debates e relatos de experiências internacionais para sistematizar o documento. Esses grupos que muitas vezes se misturam ao papel do Estado defendem a livre iniciativa do capital e propõe que o Estado divida, ou transfira a responsabilidade para o setor privado. Essa descentralização para o mercado [...] outorga novas funções aos governos central, estadual e/ou municipal alcançando também o âmbito escolar. Na definição da BNCC, não é diferente, tal fenômeno político que resulta de uma nova pedagogia da hegemonia, [...] tem inspirado o projeto de atualização da agenda da social democracia no mundo. Ao descrever o processo de interferência do setor privado na definição das públicas educativas, assim detalha Cury (1992, p. 42): “um grupo restrito de empresários do ensino, exatamente pela posse de um novo conteúdo econômico (posse do know-how) torna-se 'irradiador de prestígio', na expressão de Gramsci (1978) e, por isso, postula um novo conteúdo político (direção cultural) [...]" acusando o Estado como incapaz de definir novos rumos para a educação brasileira (TRICHES, 2018, p. 76).
\end{abstract}

No entanto, essa atuação não se dá de forma avessa ao Estado, mas com ele, modificando a cultura das organizações. Esse grupo de empresários não se opõe ao Estado. Pelo contrário, atua por meio e com o Estado (PERONI; CAETANO, 2015), modificando a cultura organizacional, adotando uma política de new public management. Ou seja, através da adoção de instrumentos de accountability, de prestação de contas, de uma política neoliberal, com características do setor privado, sustenta que o Estado deve aprender com as qualidades do setor privado, como a flexibilidade, a inovação, a eficiência e a eficácia em suma, todos os valores reivindicados pelo mercado.

A Undime e o CONSEd ficaram incumbidas do desenvolvimento de audiências públicas, de conferências que buscaram a formulação da alternativa, e estes, por sua vez, vinculavam-se às já referidas fundações e ao Movimento pela Base Nacional Comum. É importante ressaltar que tais mecanismos de articulação são compostos basicamente pelos mesmos atores, a maioria integrando a Fundação Lemann, como apresenta o esquema a seguir, na Figura 2, elaborado por Peroni e Caetano (2015), mapeando quem são os sujeitos do Movimento pela Base Nacional Comum e qual rede articulam, de modo a defender os interesses de grupos ou comunidades políticas - utilizando-as como ferramenta adicional de mobilização.

Figura 2 - Sujeitos do Movimento pela Base Nacional Comum 


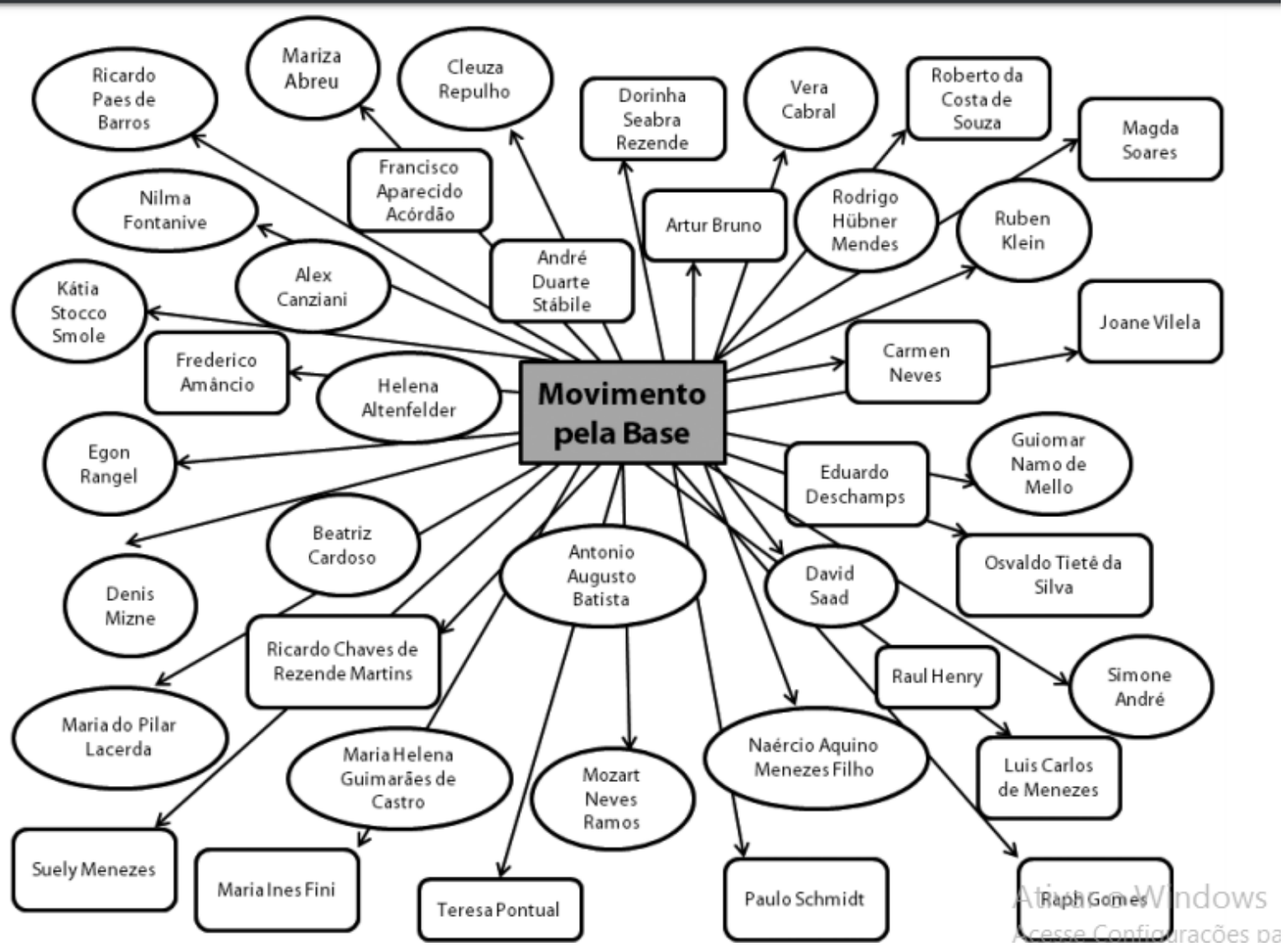

Fonte: Peroni e Caetano (2015).

$\mathrm{Na}$ Figura 2, os atores nomeados dentro de uma elipse são os representantes dos agentes privados; já nos retângulos, são os agentes ligados às instituições públicas. Convém destacar que alguns destes agentes, influentes no Movimento pela Base Nacional Comum, já atuaram no setor público como gestores de políticas educacionais, entre os quais se pode citar Cleusa Repulho, que foi presidenta da União Nacional dos Dirigentes Municipais de Educação (Undime), cargo que ocupou entre 2011 e 2015, além de ter ocupado cargos na gestão da educação municipal de Santo André e de São Bernardo do Campo (SP), dentre outros exemplos.

\section{Um protagonismo suprimido: outros atores, ideologias e valores em disputa}

Diferentemente do Movimento pela Base Nacional Comum, há atores sem financiamento corporativo e com dificuldades de trânsito no espaço político de articulação das políticas públicas. Sem espaço assegurado de participação, questionam a legitimidade do documento, bem como as reais motivações e interesses não esclarecidos no processo de formulação da Base Comum. Indagam ainda o sentido da política de educação proposta para o país. Estes atores, com menor protagonismo durante o processo, mobilizaram-se, questionando-o sobre suas etapas, alertando para a necessidade de uma maior participação. 
As críticas em relação aos movimentos pró-BNCC fundamentam-se na afirmação de que as interferências da lógica empresarial e da ideia de meritocracia não seriam adequadas às políticas de educação, haja vista o cenário de desigualdade que permeia o sistema brasileiro de educação. A argumentação de movimentos contrários à Base Nacional organiza-se a partir dos aspectos relacionados a avaliações em larga escala - os testes padronizados -, ocorrendo distorções do ponto de vista pedagógico e da função que a educação exerce no país.

A ANPEd divulgou uma série de reflexões e questionamentos sobre a organização do documento de referência. Inicia uma das notas reiterando o compromisso com o desenvolvimento da educação, da ciência e da cultura, e indagando sobre quais os atores que participaram do debate, expondo a deposição da presidenta eleita em 2016, apontando para uma estagnação do processo. O fato de a aprovação da BNCC do Ensino Médio ocorrer em período posterior ao da Educação Infantil e Ensino Fundamental foi considerado simbólico, desagregando, de forma prática, o Ensino Médio das demais etapas. O processo de construção e formulação, protagonizado por especialistas, ocorre, conforme a nota, devido ao fato de que a Base

subalterniza o diálogo com as comunidades escolares quanto suas evidentes implicações nos processos de avaliação, de ensino e aprendizagem, na homogeneização das matrizes curriculares, na formação de professores e autonomia das escolas que se fragilizam com a lógica de centralização que a BNCC instaura na educação escolar (ANPED, 2017).

Outra crítica se dá em relação à construção e aos estudos já realizados acerca de bases formuladas e implementadas em países como Chile, Austrália e Estados Unidos da América, que adotam o modelo Commom Core. A maioria dos estudos posicionou-se de forma crítica, segundo a ANPEd. A ideia de competências também envolve uma discussão conceitual, visto que, segundo a BNCC (BRASIL, 2017), competência

é definida como a mobilização de conhecimentos (conceitos e procedimentos), habilidades (práticas, cognitivas e socioemocionais), atitudes e valores para resolver demandas complexas da vida cotidiana, do pleno exercício da cidadania e do mundo do trabalho. (BRASIL, 2018, p. 8).

Este conceito retoma uma discussão bastante presente no final da década de 1990, quando são organizados os Parâmetros Curriculares Nacionais, que norteiam a formação dos currículos locais, no entanto, tal documentação não tinha a mesma força que a Base Nacional por se tratar de um parâmetro e não uma normatização.

Além de terem sido percebidas nas ocasiões formais de participação, as regularidades práticodiscursivas do polo da crítica ecoaram também a partir de eventos acadêmicos e de documentos, como manifestos, cartas abertas e abaixo-assinados. A Confederação Nacional dos Trabalhadores da Educação (CNTE), que reúne sindicatos da categoria, apresentou forte oposição à BNCC ao longo de todo o processo. A entidade organizou eventos paralelos às audiências regionais do $\mathrm{CNE}$, apresentados

como forma de denúncia à tendência privatista da educação básica pública no Brasil e o empobrecimento do currículo das escolas. [...] a redação do documento foi feita sem a 
participação social e há a necessidade de ser discutida a partir da escola, como determina a Lei de Diretrizes e Bases da Educação Nacional, e não de dentro do MEC [...]. O objetivo é que as reflexões, coordenadas pelas entidades populares, fomentem novo parâmetro na discussão da Base, com enfoque voltado à defesa intransigente da educação pública, de boa qualidade e socialmente referenciada, além de permitir a participação efetiva da sociedade civil organizada [...]. (CONFEDERAÇ̃̃O NACIONAL DOS TRABALHADORES DA EDUCAÇÃO, 2017 apud MICHETTI, 2018, p. 17-18).

Ainda, outras entidades se manifestam durante o processo de formulação, complementando o posicionamento da Confederação Nacional dos Trabalhadores em Educação, apresentando uma série de documentos, cartas abertas, abaixo-assinados, manifestos, dentre outros mecanismos de divulgação dos posicionamentos. A Campanha Nacional pelo Direito à Educação (CNDE) também se manifestou contrária ao consenso da Base, articulado pelos movimentos de maior protagonismo que, em colaboração com o MEC, foram decisivos na formulação da regulação da política pública, alertando à comunidade educacional que a possível implementação da BNCC na sociedade civil

deve gerar forte e justificada oposição da comunidade educacional, que se espalha por todo o país e é muito mais ampla em representatividade e pluralidade do que o grupo que interage e busca legitimar - ainda que de forma constrangida - o MEC, composto por poucas associações de base empresarial, praticamente restritas à ponte área São Paulo-Rio de Janeiro. (MICHETTT, 2018, p. 19).

As fundações têm pressa, devido às metas impostas. Assim, a preocupação com a discussão, conforme os críticos, deu-se mais para cumprimento de burocracias do que para utilização de falas e contribuições que propusessem a revisão do que estava posto. A legitimação do processo, portanto, mostrou-se duvidosa, tendo em vista que nem todos os atores da política de regulação se sentiram contemplados na participação, o que pode colocar em dúvida a formulação deste fluxo de soluções. Tal argumentação embasa futuros questionamentos que visam discutir se tal fluxo ocorreu de forma top down ou bottom up, o que poderia gerar subsísio para o avanço desta agenda de pesquisa.

O fato é que há fortes indicativos de que a formulação da BNCC seguiu um modelo top down, baseado numa escolha política centralizada, que mais atende aos pressupostos e interesses daqueles que estão acima na hierarquia, os chamados de burocratas de alto escalão. Pouco espaço democrático foi assegurado para questionamento por parte dos implementadores, que ocupam níveis mais baixos da administração e com grau de discricionariedade. Em suma, evidenciam-se disputas e abrem-se caminho para indagação acerca dessa política educacional: houve participação da sociedade civil em sua construção? Aqueles atores que não ocupam cargos nos espaços financiados por corporações foram representados, ouvidos e tiveram sua participação assegurada? Não há elementos explícitos nessa disputa que nos permitam uma conclusão peremptória, pela própria natureza da atuação dos grupos de pressão e influência, nem sempre ostensivas. O questionamento, no entanto, precisa ser bem marcado. A análise de diferentes atores, selecionados para uma investigação que não se esgota no presente estudo, permite a problematização das relações operantes e serve de elemento para subsidiar novas discussões. 


\section{Contexto jurídico-legal que embasa a construção de um currículo com base comum}

A história do Brasil foi marcada por uma série de disputas envolvendo diferentes atores, contextos e forças. O processo de redemocratização, que se inicia na década de 1980, evidencia avanços relacionados aos direitos sociais que se normatizam em 1988, com a promulgação da Constituição Federal. O documento originou-se de um processo de disputas, que culminou na garantia de direitos civis, políticos e sociais, como o acesso e permanência na educação básica, a saúde e as liberdades individuais. A chamada Constituição Cidadã, que organizava o Estado Brasileiro, determinava o papel das instituições e impunham desafios ao Estado, que teria de formular e implementar políticas públicas, elaborando estratégias que contribuíssem e fossem ao encontro da expectativa de direito prevista na esfera jurídica. Nesse novo contexto, a educação foi assegurada a partir do artigo 205 da Constituição Federal de 1988.

Art. 205. A educação, direito de todos e dever do Estado e da família, será promovida e incentivada com a colaboração da sociedade, visando ao pleno desenvolvimento da pessoa, seu preparo para o exercício da cidadania e sua qualificação para o trabalho. (BRASIL, 1988).

Garantido através da Lei, o acesso à educação e à permanência continuaram a desafiar gestores públicos na formulação de uma política de educação que chegasse aos diferentes segmentos sociais da população brasileira. No entanto, para a efetivação desse direito, a Lei Maior propõe, no Capítulo III, que trata "da educação, da cultura e do desporto", especificamente na seção I, que: “Art. 210. Serão fixados conteúdos mínimos para o ensino fundamental, de maneira a assegurar formação básica comum e respeito aos valores culturais e artísticos, nacionais e regionais" (BRASIL, 1988).

Ou seja, o Artigo 210 evidencia a necessidade de conteúdos mínimos, fazendo menção a uma Base Comum do Currículo Nacional. A partir destas novas perspectivas em relação à educação no país, inicia-se a construção da Lei De Diretrizes e Bases da Educação Nacional, sancionada em 1996, que reforça e aponta para a necessidade da regulamentação de uma Base Nacional Comum, destinada à educação básica, no seu artigo 26 .

Art. 26. Os currículos do ensino fundamental e médio devem ter uma base nacional comum, a ser complementada, em cada sistema de ensino e estabelecimento escolar, por uma parte diversificada, exigida pelas características regionais e locais da sociedade, da cultura, da economia e da clientela. (BRASIL, 1996).

Cabe ressaltar que o artigo anteriormente elencado sofreu alterações em 2013, a partir da Lei 12.796 (BRASIL, 2013), que incluiu a Educação Infantil na Educação Básica, como direito das crianças e dever do Estado em oferecê-la.

No entanto, mesmo com a força da lei, a regulamentação prevista na Constituição Federal (BRASIL, 1988) e reforçada na Lei de Diretrizes e Bases (BRASIL, 1996), apontando a necessidade de uma Base, fica em stand by. Em 2014, entra na agenda política a Construção da Base Nacional, reforçada pelo Plano Nacional de Educação (PNE), oriundo de uma série de discussões que considerou os diferentes atores envolvidos na educação. O processo de formulação do Plano Nacional ocorreu de forma 
bottom up, com a participação de diferentes segmentos sociais como professores, entidades classistas, fundações, Ministério da Educação e Desenvolvimento Social, dentre outros grupos interessados na discussão do Plano, que teve sua aprovação em 2014, através da Lei 13.005/2014 (BRASIL, 2014). Ressalta-se, aqui, a construção do referido Plano, pela sua relevância, crucial para o desencadeamento da BNCC.

O PNE, dentre as metas e diretrizes estabelecidas, definiu como estratégia a formulação de uma Base Nacional Comum, formulada em regime de colaboração, que necessitaria ser aprovada pelo Conselho Nacional de Educação, estando prevista uma consulta pública nacional. O documento contemplaria os direitos e objetivos de aprendizagem e desenvolvimento dos alunos.

A Base Nacional começou a ser discutida no período de formulação do Plano Nacional, em movimentos como a $2^{a}$ Conferência Nacional pela Educação (CONAE), organizada pelo Fórum Nacional de Educação (FNE), tornando-se o motor que impulsionou as discussões, gerando a mobilização para discussões propositivas em relação ao documento que nortearia a formação dos currículos locais.

Efetivou-se, então, a formulação da Base Nacional que, aprovada pelo Conselho Nacional de Educação, foi homologada - inicialmente a parte correspondente à Educação Infantil e ao Ensino Fundamental - pelo presidente da República. Só em 2018, a segunda etapa, correspondente ao Ensino Médio, foi homologada e o processo de implementação iniciou-se em todo o país.

Diante do exposto, alguns atores e movimentos se destacaram na construção deste documento, em especial fundações privadas, financiadas por grandes empresários, os quais, interessados pela Educação Brasileira, passaram a figurar como protagonistas das discussões e do financiamento do processo de formulação e implementação dessa política nacional.

Figura 3 - Síntese do Processo de Construção da Base Nacional Comum

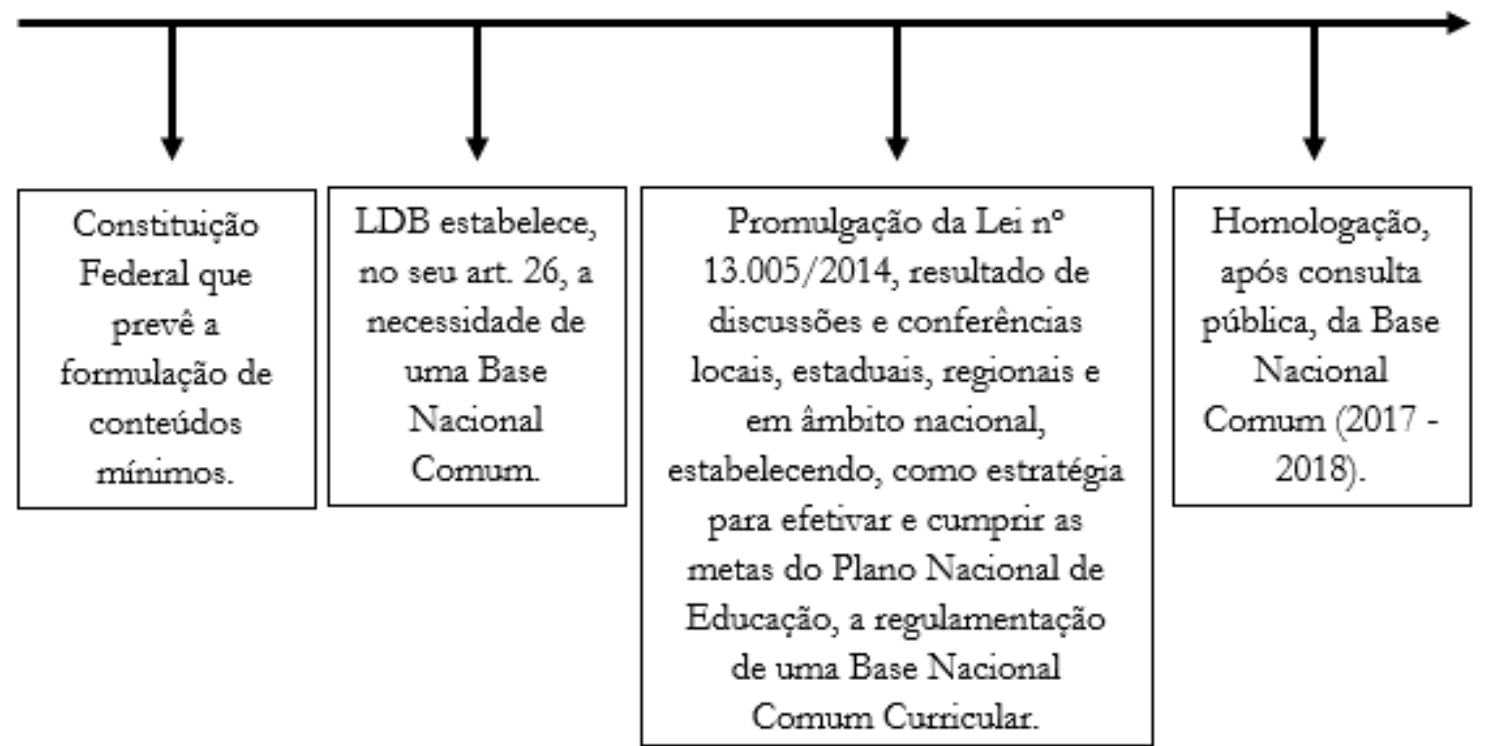

Fonte: elaboração própria. 
O quadro acima ilustra o processo de construção da BNCC até a sua homologação em 2017 e 2018. É importante destacar que, o quadro sintetiza apontando marcos legais (CF, 1988; LDB 9.394/96, PNE 13.005/14), mas não ilustra os movimentos, as disputas e tensões que permearam todo o processo. Além disso, não contempla, por exemplo, o processo de Impeachment sofrido pela ex-presidente Dilma Rousseff, em 2016, acusada de um crime de responsabilidade e, que demandaria esforço de pesquisa e, a construção de um segundo trabalho, a fim de contemplar a complexidade do ocorrido. Este registro é relevante, na medida em que no período de deposição de Rousseff, o país discutia as estratégias, as metas e princípios construídos no Plano Nacional de Educação e, articulavam-se movimentos de elaboração da BNCC que já ocorria no âmbito federal, desde a última Conferência Nacional de Educação.

\section{Considerações finais}

A política pública surge a partir do momento em que um problema é notadamente público. O presente estudo evidencia a discussão sobre a Base Nacional Comum e a enquadra na categoria de problema público, na medida em que a questão da educação atinge um notável número de pessoas, as estatísticas e os índices de qualidade. Por meio de um conjunto de avaliações externas, evidencia o baixo rendimento do país nestes indicadores, que, por sua vez, remetem a questões envolvendo o financiamento, oriundo de organismos internacionais. Além disso, o conceito e os desdobramentos da compreensão sobre política pública remetem-nos a algo já exposto por estudiosos, os quais expõem que as políticas públicas não se restringem aos atores do Estado, tanto no processo de formulação quanto implementação, mas que são formuladas a partir da sociedade civil, entidades e organizações. Neste caso, algumas das participações ocorrem com maior protagonismo. $\mathrm{Na}$ formulação de alternativas, na construção da Base Nacional, atores mobilizaram-se e evidenciaram a disputa que permeia a adesão de alguns valores, de alguns projetos políticos em detrimento de outros. Desta forma, compreendendo que as Políticas Públicas se firmam a partir da contribuição de atores, jogos políticos, barganhas e disputas, a Base e sua formulação construiu-se com a participação de entidades com financiamento privado, representando, a partir dessa perspectiva, uma outra forma de conceber e conduzir a gestão das políticas. Os estudos teóricos da Ciência Política já apontavam para uma nova forma de gerenciamento das políticas, adotando-se princípios oriundos da gestão corporativa, associando o mercado, com a ideia de lucro, produtividade e capital, a princípios da solidariedade, representados pela sociedade e hierarquias representadas pelo Estado.

A política de formulação da BNCC ocorreu com a participação de atores da sociedade civil organizada e do poder executivo, representado pelo Ministério da Educação, embora esta instância de gestão delegou grande parte da atribuição a atores e movimentos políticos públicos, vinculados, de certo modo, com grupos de interesses do segmento corporativo. A demanda, o problema público e a solução deste segue uma lógica do accountability, de prestação de contas para a sociedade civil e o mercado, sendo 
depositada na BNCC a possível redução dos problemas, evidenciados a partir de exames de larga escala e índices de qualidade que apontam para uma necessidade de reformulação. Uma outra discussão teórica a que o artigo se propôs foi a identificação de que alguns atores, mesmo sem a busca pelo lucro diretamente, influenciaram nas decisões, através de financiamento, mobilização e trânsito político, nos espaços de poder e representação - alguns destes atores, públicos e com presença notória nos meios de comunicação e nos espaços de discussão da educação. Em contrapartida, há os investidores que financiaram os movimentos, como a Fundação Lemann, que contribuiu para o Movimento pela Base Nacional Comum, trazendo à tona sua visão acerca da condução da política pública, apontando para uma interferência nas políticas públicas de entidades, fundações que não estão vinculadas à estrutura estatal. O questionamento principal foi sobre quem são os atores, identificados então como fundações e entidades sem fins lucrativos, mas vinculadas a corporações que tiveram maior protagonismo e participação legitimada por aqueles que detinham o poder de fala, registro e ponderações. O objetivo do artigo era discutir de que modo tais atores contribuíram na busca de soluções, quais os interesses desses atores e as estratégias adotadas para garantir a participação. Daí a observação de grande investimento de corporações, de fundações com lógicas adversas a entidades como ANPEd, ABdC, entre outros agentes que questionam a legitimidade do processo, bem como discutem a garantia dos aspectos democráticos, de participação e de que a educação não se restrinja aos interesses mercantis, não ceda às lógicas do capital financeiro que buscam a formação de mão de obra - adotando-se um neoliberalismo na educação, a partir do princípio de gestão eficiente.

Observou-se, também, a rede de relações que atuaram na formulação da alternativa, identificando atores que transitam entre o público e o privado, defendendo grupos de interesse, projetos políticos e acirrando disputas, conflitos, cooperações para a construção da regra, a partir de uma visão multicêntrica, que considera os diferentes atores políticos na formulação e implementação de políticas públicas.

Deste modo, as discussões iniciadas no presente trabalho não têm a pretensão de encerrá-las. Pelo contrário, buscou-se, por meio de levantamento de um estudo de caso, destacar a participação de determinados atores, a fim de discutir e aprofundar a análise sobre os interesses em disputa na formulação de uma política pública educacional, buscando responder às indagações iniciais. Assim, analisar a participação destes atores nos permite concluir que a educação, enquanto política pública, precisa de programas mais amplos, que ultrapassem o mandato dos governos. Todavia, deve-se observar as participações sociais e os objetivos de determinados grupos de interesses, a fim de identificar o que buscam, através do quê, e os efeitos dessas soluções para problemas públicos.

\section{Referências:}


ANTUNES, André. A quem interessa a BNCC? EPSJV/Fiocruz, 23 nov. 2017. Disponível em: http://www.epsjv.fiocruz.br/noticias/reportagem/a-quem-interessa-a-bncc. Acesso em: 14 jul. 2019.

Associação Nacional de Pós-graduação e Pesquisa em Educação (ANPED). Exposição de motivos sobre a Base Nacional Comum Curricular. [Ofício], ao Conselho Nacional de Educação, Rio de Janeiro, 9 nov. 2015.2 Disponível em: http://www.anped.org.br/sites/default/files/resources/Of_cio_01_2015_CNE_BNCC.pdf. Acesso em: 14 jul. 2019.

Associação Nacional de Pós-graduação e Pesquisa em Educação (ANPED). Nota da ANPEd sobre a entrega da terceira versão da Base Nacional Comum Curricular (BNCC) ao Conselho Nacional de Educação (CNE). [Nota], abr. 2017. Disponível em: http://www.anped.org.br/sites/default/files/nota_da_anped_sobre_a_entrega_da_terceira_versao_da_b ase_nacional_comum_curricular_abril_2017.pdf. Acesso em: 08 jul. 2019.

BENTO, Juliane S. Da crítica da política à gestão pública eficaz: a despolitização como estratégia de poder. Debates, v. 12, n. 3, 2018. P. 107-122. Disponível em: https://doi.org/10.22456/19825269.85870. Acesso em 24 ago. 2020.

BRASIL. Base Nacional Comum Curricular: Educação Infantil e Ensino Fundamental. Brasília: MEC/Secretaria de Educação Básica, 2017.

BRASIL. Constituição (1988). Constituição da República Federativa do Brasil de 1988. Disponível em: http://www.planalto.gov.br/ccivil_03/constituicao/constituicao.htm. Acesso em: 04 jul. 2019.

BRASIL. Lei $\mathrm{n}^{\circ}$ 9.394, de 20 de dezembro de 1996. Estabelece as diretrizes e bases da educação nacional. Disponível em: http://www.planalto.gov.br/ccivil_03/ leis/19394.htm. Acesso em: 16 mar. 2019.

BRASIL. Lei $\mathbf{n}^{\mathbf{0}}$ 12.796, de 4 de abril de 2013. Altera a Lei n. 9.394 de 20 de dezembro de 1996, que estabelece as diretrizes e bases da educação nacional, para dispor sobre a formação dos profissionais da educação e dar outras providências. Disponível em: http://www.planalto.gov.br/ccivil_03/_ato20112014/2013/lei/112796.htm. Acesso em: 11 jul. 2019.

BRASIL. Lei n.13.005, de 25 de junho de 2014. Aprova o Plano Nacional de Educação - PNE e dá outras providências. Diário Oficial da União, Brasília, DF, 26 jun. 2014. Disponível em: https://www.planalto.gov.br/ccivil_03/_ato2011-2014/2014/lei/113005.htm. Acesso em: 08 jul. 2019.

BRASIL. Base Nacional Comum Curricular. Brasília: MEC/Secretaria de Educação Básica: 2018. Disponíve

http://basenacionalcomum.mec.gov.br/images/BNCC_EI_EF_110518_versaofinal_site.pdf. Acesso em: 13 jul. 2019.

BRITTO, Tatiana Feitosa de. O livro didático, o mercado editorial e os sistemas de ensino apostilados. Centro de Estudos da Consultoria do Senado. Brasília: Senado Federal, 2011. Disponível em: https://www12.senado.leg.br/publicacoes/estudos-legislativos/tipos-de-estudos/textos-paradiscussao/td-92-o-livro-didatico-o-mercado-editorial-e-os-sistemas-de-ensino-apostilados. Acesso em: 14 jul. 2019.

CAPELLA, Ana Cláudia Niedhardt. Formulação de Políticas Públicas. Brasília: ENAP, 2018. (Coleção Governo Políticas Públicas). Disponível em: https://ppgcsunisinos.files.wordpress.com/2019/05/livro_formulac3a7c3a3o-de-polc3adticaspc3bablicas-1.pdf. Acesso em: 12 jul. 2019.

CORREAA, Adriana; MORGADO, José Carlos. A construção da Base Nacional Comum Curricular no Brasil: tensões e desafios. In: IV COLÓQUIO LUSO-BRASILEIRO DE EDUCAÇÃO, 2018, Braga e Paredes de Coura, Portugal. Currículo e inclusão em tempos de internacionalização. Portugal/Brasil: UDESC, 2018. Disponível em: http://www.revistas.udesc.br/index.php/colbeduca/issue/view/591. Acesso em: 04 jul. 2019. 
FUNDAÇÃO

LEMANN.

Relatório

2002.

Disponível

em

https://fundacaolemann.org.br/uploads/arquivos/ra_2002.pdf. Acesso em: 24 de agosto de 2020.

MARINHO, Genilson Cordeiro. Os Parâmetros Curriculares Nacionais no contexto das reformas neoliberais: o caso de geografia. 2003. Disponível em https://repositorio.ufpe.br/bitstream/123456789/4791/1/arquivo5974_1.pdf acesso em 24 de agosto de 2020.

MEGALE, Caio. Educação, produtividade e crescimento. Valor Econômico, 26 jan. 2016. Disponível em: https://www.valor.com.br/opiniao/4409538/educacao-produtividade-e-crescimento. Acesso em: 14 jul. 2019.

MICHETTI, Miqueli. Atuação de elites empresariais na definição dos rumos da educação pública no Brasil contemporâneo. In: 42 ${ }^{\circ}$ Encontro Anual da Anpocs, 2018, Caxambu, MG. Caxambu: Anpocs, 2018. p. 1-27. Disponível em: https://www.anpocs.com/index.php/papers-40-encontro-3/gt-31/gt1025/11195-a-atuacao-de-elites-empresariais-na-definicao-dos-rumos-da-educacao-publica-no-brasilcontemporaneo/file. Acesso em: 11 jul. 2019.

MICHETTI, Miqueli. A vida como projeto: a pedagogia do homo economicus e as iniciativas de fomento ao "espírito do capitalismo" via educação pública. Ciências Sociais Unisinos, v. 55, n. 3, 2019. P. 302314.

Disponível

em: http://revistas.unisinos.br/index.php/ciencias_sociais/article/view/csu.2019.55.3.01. Acesso em 24 ago. 2020 .

MOVIMENTO PELA BASE NACIONAL COMUM. Necessidade e construção de uma Base Nacional Comum. [2019?]. Disponível em: <http://movimentopelabase.org.br/wpcontent/uploads/2015/09/Necessidade-e-construcao-Base-Nacional-Comum.pdf $>$. Acesso em: 09 jul. 2019 .

PERONI, Vera Maria Vidal; CAETANO, Maria Raquel. O público e o privado na educação: projetos em disputa? Revista Retrados da Escola, v. 9, n. 17. p. 337-352, jul./dez. 2015. Disponível em: http://retratosdaescola.emnuvens.com.br/rde/article/viewFile/584/658. Acesso em 08 jul 2019.

RUA, Maria das Graças; ROMANINI, Roberta. Teorias e modelos de análise contemporâneos de políticas públicas (unidade VII). In: Para aprender políticas públicas: conceito e teorias. v. 1. Brasilia: IGEPP, 2014. Disponível em: http://igepp.com.br/uploads/ebook/para_aprender_politicas_publicas__unidade_07.pdf. Acesso em: 11 jul. 2019.

TRICHES, Eliane de Fátima. A formulação da Base Nacional Comum Curricular (BNCC) e concepções em disputa sobre o processo alfabetizador da criança. 2018. 162 f. Dissertação (Mestrado em Educação) - Programa de Pós-Graduação em Educação, Universidade Federal da Grande Dourados (UFGD), Dourados, $2018 . \quad$ Disponível http://files.ufgd.edu.br/arquivos/arquivos/78/MESTRADO-DOUTORADOEDUCACAO/Eliane $\% 20$ Triches $\% 20$ \%20Disserta \%C3\%A7\%C3\%A3o\%20finalizada\%2022.04.2018\%20cat\%201.pdf. Acesso em: 02 jul. 2019.

YAZAN, Bedrettin. Tres abordagens do método de estudo de caso em educação: Yin, Merriam e Stake. Revista Meta: Avaliação, v. 8, n. 22, p. 149-182, may 2016. ISSN 2175-2753. Disponível em: http://revistas.cesgranrio.org.br/index.php/metaavaliacao/article/view/1038. Acesso em: 24 aug. 2020. doi:http://dx.doi.org/10.22347/2175-2753v8i22.1038.

\section{Notas}


1 Doutorando em Ciências Sociais (UNISINOS). Mestre em Ciências Sociais e graduado em Pedagogia e Ciências Sociais. Integrante do grupo de pesquisa Políticas Públicas, Direitos e Democracia (UNISINOS). Professor adjunto de Ciência Política Uniftec e de Sociologia da Educação Básica. Currículo Lattes: http://lattes.cnpq.br/2340456301288866 Orcid: https://orcid.org/0000-0002-8029-5237.E-mail: cristian-tisatto@hotmail.com

2Doutora em Ciência Política (UFRGS). Professora no Programa de Pós-Graduação em Ciências Sociais da Escola de Humanidades da Universidade do Vale do Rio dos Sinos (Unisinos). Pesquisadora do Núcleo de Estudos em Justiça e Poder Político (Nejup/UFRGS) e do Grupo de pesquisa Políticas públicas, direitos e democracia (UNISINOS). Currículo Lattes: http://lattes.cnpq.br/4806556228518727. Orcid: https://orcid.org/0000-0001-9978-1289. E-mail: julianebento@unisinos.br.

3 A Associação Brasileira de Currículo (ABdC) é uma associação civil sem fins lucrativos e econômicos, caracterizando-se como pessoa jurídica de direito privado, criada em 08/06/2011, em Assembleia de fundação realizada durante o VI Seminário Internacional "As Redes educativas e as tecnologias: práticas/teorias sociais na contemporaneidade", na cidade do Rio de Janeiro, congregando os profissionais, pesquisadores, estudantes que realizam atividades de pesquisa e/ou docência e extensão no campo do Currículo.

${ }^{4}$ A Homologação da Base Nacional Comum Curricular ocorreu em dois momentos: o documento referente à Educação Infantil e ao Ensino Fundamental foi homologado em dezembro de 2017. Já o documento do Ensino Médio foi aprovado somente em 2018, visto que esta etapa da Educação Básica exigiu mais discussão - considerando que o MEC já organizava uma "reforma" no Ensino Médio.

5 Disponível em: http://movimentopelabase.org.br/quem-somos/. Acesso em: 12 jul. 2019.

${ }^{6}$ Com base no site do Movimento pela Base Nacional Comum. Disponível em: http://movimentopelabase.org.br/quem-somos/. Acesso em: 12 jul. 2019.

Recebido em: 03 de fevereiro de 2021

Aprovado em: 23 de agosto de 2021 